\title{
The Effects of Chronic Administration of Excess Iodine on Thyroidal Hormone Synthesis in the Chick*
}

\author{
HOJ SUZUKI, MITSUO SAWADA, KAZUKO TAKAHASHI, \\ KEISUKE TAKEUCHI AND YOSHIHIKO HORIUCHI \\ The Second Department of Internal Medicine, \\ School of Medicine Hokkaido University, Sapporo
}

\begin{abstract}
Synopsis
The response of thyroid weight and iodine metabolism to excess ingestion of iodide was studied in the chick. Treatment of chicks with $1 \mathrm{mg}$ of iodide for 4 weeks induced a marked increase in thyroid weight. The radiochromatography of the 131 I labelled thyroid hydrolysate showed that a single injection of carrier iodide resulted in a significant but transient reduction of a relative proportion of organic 131 I as well as thyronine 131I and an elevation of the MIT/DIT ratio. After chronic treatment of chicks with excess iodide, the thyronine 131 I proportion was still decreased notwithstanding the fact that the organic $131 \mathrm{I}$ proportion showed a return to normal and MIT/DIT was rather low. The increased thyroid weight and decreased thyronine proportion returned to normal 9 weeks after termination of the iodide feeding. In the goitrous chicks, the relative proportion of intrathyroidal 127I compounds were virtually identical with that of 131 I, although the absolute amount of thyronine 127I was increased depending on the increase in total $127 \mathrm{I}$ content. There was no significant difference in both turnover rate of radiothyroxine and plasma thyronine 127I concentration between the goitrous and control chicks. It is suggested that these alterations of iodine metabolism seem to be closely related to the mechanism of goitrogenesis by excess iodide in chicks and may represent an inhibitory effect of iodide on intrathyroidal hormogenesis.
\end{abstract}

The effect of a large amount of iodide on the thyroid varies with the species (Pitt-Rivers 1960). Wheeler and Hoffman (1948, 1949) first demonstrated goiter in chicks or adult hens by chronic treatment with iodine. On the other hand the rat is resistant to goiter production even by massive doses of iodine (Galton and Pitt-Rivers 1959).

In human subjects, Morgans and Trotter (1953) and others have observed that goiters develop in a small percentage of patients taking iodide compounds for the treatment of asthma or brochitis. We reported on endemic coast goiters in Hokkaido where inhabitants ingest a

Received for publication June 26, 1969.

* This study was supported in part by Grant No.481/ RB from International Atomic Energy Agency. large amount of iodide from kelp (Suzuki et al., 1965). Although the mechanism of goitrogenic effects of iodine has not been completely clarified, the present study was undertaken to study the response of thyroidal hormone synthesis to acute and chronic administration of excess iodide in the chick.

\section{Materials and Methods}

\section{Animals}

Male or female White-Rock chicks, 9 to 14 weeks of age, weighing 900 to $1,500 \mathrm{~g}$, were fed a commercial diet throughout the experimental period. The iodine content of the diet was approximately $0.2 \mu \mathrm{g} / \mathrm{g}$.

In the experiments in which acute effect of iodide was studied, chicks were given a single injection of 131 I (100 $\mu \mathrm{Ci}$ of $\left.\mathrm{Na}{ }^{131} \mathrm{I}\right)$ and carrier iodide (1 mg of 
iodide as KI) intraperitoneally. Control chicks were injected with $10 \sim 20 \mu \mathrm{Ci}$ of $131 \mathrm{I}$ alone. After intervals of 4 to $24 \mathrm{hr}$., the chicks 'were killed by decapitation and the thyroids were removed.

In the experiments in which chronic effect of iodide was studied, chicks were given $\mathrm{KI}$ in drinking water, so that each animal received about $1.0 \mathrm{mg}$ of iodide per day. After treatment with iodide for 4 weeks, chicks were injected with $1.0 \mathrm{mg}$ iodide and $200 \mu \mathrm{Ci} 131 \mathrm{I}$. The thyroids were removed 4 and 24 hr. later respectively.

For the study of the aftereffect of a longterm treatment with iodide, the chicks receiving iodide for 4 weeks were killed for thyroid analysis 1,3 and 9 weeks after discontinuing the iodide feeding. In this experiment, chicks were injected with carrier free $131 \mathrm{I}$ and the thyroids were removed $4 \mathrm{hr}$. later.

The study of the peripheral degradation of radiothyroxine was carried out on control chicks, iodidetreated chick ( $1 \mathrm{mg}$ per day for 4 weeks), chicks treated with $50 \mathrm{mg}$ of propylthiouracil per day for 4 weeks and chicks treated with $50 \mu \mathrm{g}$ of thyroxine per day for 4 weeks.

Column chromatography for analysis of $131 \mathrm{I}$ and 127 I fractions in the thyroid

The excised thyroids were immediately frozen on dry ice, weighed and homogenized in Krebs-Ringerphosphate buffer $(1.0 \mathrm{cc} / 100 \mathrm{mg}$ tissue at $\mathrm{pH} 7.4)$ containing methylthiouracil $(100 \mu \mathrm{g} / 100 \mathrm{mg}$ tissue $)$. The homogenates were hydrolysed with trypsin and pancreatin $(7.0 \mathrm{mg} / 100 \mathrm{mg}$ thyroid tissue respectively) in the presence of toluen for $24 \mathrm{hr}$. at $37^{\circ} \mathrm{C}$. An aliquot of the hydrolysate was adjusted to $\mathrm{pH} 4.0$ and then subjected to column chromatography according to the method of Pileggi et al. (1961, 1964).

In order to determine whether or not the column procedure would be applicable to the determination of radioaminoacids in the thyroid, 131 I labelled monoiidotyrosine (MIT), diiodotyrosine (DIT) and thyroxine $\left(\mathrm{T}_{4}\right)$ were added to the thyroid homogenates and then evaluated from the column at $\mathrm{pH}$ $3.6,2.2$ and 1.4 respectively. The recovery of the radioiodo-compounds from thyroid homogenates was $98.2 \%$ for MIT, $96.9 \%$ for DIT and $97.5 \%$ for $\mathrm{T}_{4}$. Nearly all of $\mathrm{Na} 131 \mathrm{I}$ was retained by the resin in the column.

An aliquot of the effluents from each fraction was subjected to the determination of radioactive and stable iodine. Radioactivity of $131 \mathrm{I}$ in each fraction was counted in a well-type scintillation counter and expressed as a relative proportion to the total $131 \mathrm{I}$ in the thyroid. A sum of MIT, DIT and thyronine proportions was expressed as an organic fraction. Paralleled analysis of the homogenates was made for radioiodocompounds by paperchromatography (Roche et al., 1954; Suzuki 1958), and for organic 131 I by precipitation with trichloroacetic acid (Pitt-Rivers et $a l ., 1958)$. The results were virtually identical with that of column chromatography. For the determination of stable iodine, homogenates of the pooled glands from 5 chicks were hydrolyzed and then subjected to chromatography. Analysis of the fractions for iodine content was made following the acid incineration (Gross et al., 1948).

Plasma protein-bound iodine was determined by the method of Grossman and Grossmann (1955). Plasma thyronine iodine was determined by the method of Pileggi $(1961,1964)$ with a minor modification as follows; $6.0 \mathrm{cc}$ of plasma was subjected to column chromatography using a double volume of reagents. Colorimetry of iodine in the ash was made by the same method of PBI determination as described above (Grossmann and Grossman 1955).

\section{Peripheral degradation of radiothyroxine}

$50 \mu \mathrm{Ci}$ of $131 \mathrm{I}$-labelled L-thyroxine (Abbott Laboratories) was given into a wing vein. After 7, 12, 24, 48 and $72 \mathrm{hr}$., $1.0 \mathrm{cc}$ of blood samples was collected from the other side of the wing vein in heparinized syringes. Plasma was separated by centrifugation and radioactivity of the plasma 131 I was counted as described above. Half-life of thyroxine131 I $\left(\mathrm{T}_{1} / 2\right)$, thyroxine distribution space (TDS) were calculated according to the method of Ingbar and Freinkel (1955).

\section{Results}

\section{Acute effect of iodide}

As shown in Figure 1, in the chicks injected with a single dose of $131 \mathrm{I}$ and ${ }^{127} \mathrm{I}$, the relative proportion of organic ${ }^{131} \mathrm{I}$ in the thyroid was significantly decreased $4 \mathrm{hr}$. after the injection $(\mathrm{p}<0.001)$. Thereafter it gradually increased, but $24 \mathrm{hr}$. later it failed to attain the control level. MIT/DIT ratios in the iodide-treated chicks were significantly higher than control during the first $16 \mathrm{hr}$. following the injection ( $\mathrm{p}<0.001$ respectively). After $24 \mathrm{hr}$. it returned to the control level. 131I thyronine proportion in the iodide-treated chicks was smaller than the corresponding control value throughout the period ( $\mathrm{p}<0.001$ respectively). 


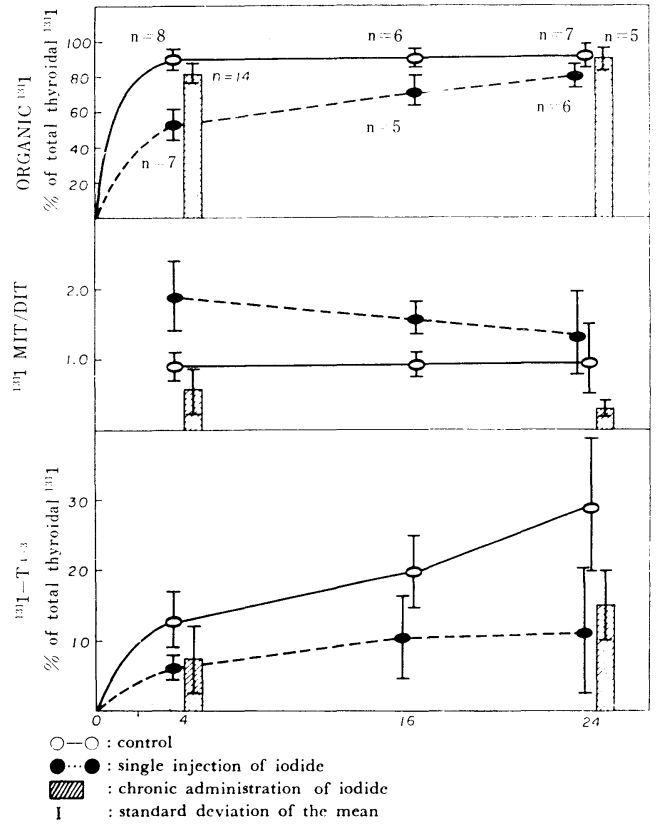

Fig. 1. Effect of iodide on the radioiodinated compounds in the thyroid of chicks given carrier free 131 I (open circles), 131 I with $1.0 \mathrm{mg}$ of carrier iodide (solid circles) and $1.0 \mathrm{mg} /$ day of iodide for 4 weeks (hatched bar).

Bracket indicates the standard deviation of the mean value.

\section{Chronic effect of iodide}

As shown in Table 1, the average thyroid weight of the chicks fed iodide was increased to about 1.8 times as much as the control. The difference between the two groups was significant $(\mathrm{p}<0.001)$.

Figure 1 also shows the chronic effects of iodide on the relative proportion of ${ }^{131} \mathrm{I}$ constituents in the thyroid. Proportions of organic ${ }^{131} \mathrm{I}$ either 4 or $24 \mathrm{hr}$. after the injection of ${ }^{131} \mathrm{I}$ were not different from the corresponding control values. MIT/DIT ratio was markedly low in the iodide-fed chicks. The ratio was not only lower than that in the chicks given a single injection of iodide, but also lower than that in the control $(\mathrm{p}<0.001$ respectively). Proportions of 131 I thyronine were significantly decreased either 4 or $24 \mathrm{hr}$. after the injection ( $\mathrm{p}<0.001$ respectively).

Total iodine content of the thyroid in the
Table 1. Effect of chronic iodide administration on thyroid weight in chicks

\begin{tabular}{lcc}
\hline Group & No. & $\begin{array}{c}\text { Thyroid weight } \\
(\mathrm{mg} / \mathrm{kg} \text { body weight })\end{array}$ \\
\hline Control & 140 & $95.2 \pm 32.8 *$ \\
\hline Iodide** & 30 & $176.2 \pm 57.4$ \\
\hline$*$ & Values represent mean \pm standard deviation \\
$* *$ & Administered 1.0 mg of iodide/day for 4 weeks
\end{tabular}

iodide-fed chicks was increased to approximately $820 \mu \mathrm{g} /$ gland, whereas it was $120 \mu \mathrm{g}$ in the control. The relative proportions of ${ }^{127} \mathrm{I}$ in the thyroidal iodocompound fractions were almost equal to those of ${ }^{131}$ I which were obtained 24 hr. after ${ }^{131}$ I injection (Table 2).

There was no significant difference of ${ }^{127} \mathrm{I}$ thyronine concentration in the plasma between the iodide-fed and control chicks, although in the former, PBI concentration was higher than in the control $(\mathrm{p}<0.001)$. The turnover rate of radiothyroxine was significantly increased in the thyroxine-treated chicks $(\mathrm{p}<0.001)$ and decreased in the PTU-treated animals $(\mathrm{p}<0.001)$. However there was no difference between the iodide-fed and control chicks (Table 3).

\section{Aftereffect of iodide feeding}

Figure 2 shows the changes in thyroid/body weight ratios and thyroidal ${ }^{131}$ I constituents after discontinuing iodide in the goitrous chicks induced by iodide feeding. The weight of thyroid remained greater than that of the control until 3 weeks after discontinuance of iodide. After 9 weeks, however, it was significantly decreased $(p<0.001)$ and returned to an almost normal level.

Radiochromatographic analysis of the thyroids showed no significant change in intrathyroidal iodoconstituents in the chicks 1 week after discontinuance of iodide feeding, as compared to the iodide-fed chicks. However, after 3 weeks the MIT/DIT ratio returned to the control level and ${ }^{131} \mathrm{I}$ thyronine proportion was still decreased. After 9 weeks the chromatogram showed no significant difference from the control. 
Table 2. Distribution of stable and radioactive iodide compounds in the chick thyroid

\begin{tabular}{|c|c|c|c|c|c|c|c|c|c|}
\hline Analysis & Group & & No. & $\begin{array}{c}\text { Total } \\
\text { iodide }\end{array}$ & $\begin{array}{l}\text { Organic } \\
\text { iodide }\end{array}$ & MIT & DIT & Thyronine & MIT/DIT \\
\hline \multirow{6}{*}{${ }^{127}{ }_{I}$} & \multirow{3}{*}{ Control } & $(\mu \mathrm{g} / \text { gland })^{*}$ & \multirow{3}{*}{5} & 120.4 & 118.4 & 41.7 & 39.4 & 38.3 & \multirow{3}{*}{1.00} \\
\hline & & & & & & & & & \\
\hline & & $(\%)$ & & - & 98.1 & 33.8 & 32.9 & 31.4 & \\
\hline & \multirow{3}{*}{ Iodide** } & $(\mu \mathrm{g} / \text { gland })^{*}$ & \multirow{3}{*}{5} & 822.0 & 759.3 & 104.5 & 529.5 & 125.3 & \multirow{3}{*}{0.20} \\
\hline & & & & & & & & & \\
\hline & & (\%) & & - & 92.4 & 12.7 & 64.4 & 15.2 & \\
\hline \multirow{2}{*}{${ }^{131} \mathrm{I}$} & Control & $(\%)$ & 5 & - & $92.2 \pm 4.5$ & $32.8 \pm 6.1$ & $31.8 \pm 8.3$ & $28.0 \pm 4.9$ & $1.05 \pm 0.55$ \\
\hline & Iodide** & $(\%)$ & 5 & - & $91.7 \pm 5.1$ & $15.2 \pm 7.8$ & $61.4 \pm 7.9$ & $15.2 \pm 4.8$ & $0.27 \pm 0.21$ \\
\hline
\end{tabular}

* Obtained from the pooled gland from 5 chicks

** Administered $1.0 \mathrm{mg} /$ day for 4 weeks

*** Analyzed $24 \mathrm{hrs}$. after injection, the data are expressed as mean and standard deviation

Table 3. Turnover of radiothyroxine and plasma hormone level in chicks fed iodide, propylthiouracil (PTU) and L-thyroxine ( $\left.\mathrm{T}_{4}\right)$

\begin{tabular}{|c|c|c|c|c|}
\hline Group & No. & $\begin{array}{c}\text { Half-life of }{ }^{131} \mathrm{I} \text {-thyroxine } \\
\text { (hr.) }\end{array}$ & $\begin{array}{c}\text { PBI } \\
(\mu \mathrm{g} / 100 \mathrm{ml})\end{array}$ & $\begin{array}{l}\text { Plasma thyronine } \\
(\mu \mathrm{g} / 100 \mathrm{ml})\end{array}$ \\
\hline Control & 8 & $9.8 \pm 1.3 *$ & $1.07 \pm 0.30$ & $0.65 \pm 0.23$ \\
\hline Iodide** & 6 & $9.9 \pm 1.4$ & $1.83 \pm 0.37$ & $0.69 \pm 0.20$ \\
\hline $\mathrm{PTU} * * *$ & 4 & $14.5 \pm 5.3$ & - & - \\
\hline $\mathrm{T}_{4} * * * *$ & 4 & $7.2 \pm 0.5$ & - & - \\
\hline \multicolumn{5}{|c|}{ * Values represent mean \pm standard deviation } \\
\hline \multicolumn{5}{|c|}{ ** Administered $1.0 \mathrm{mg}$ per day for 4 weeks } \\
\hline \multicolumn{5}{|c|}{ *** Administered $50 \mathrm{mg}$ per day for 4 weeks } \\
\hline \multicolumn{5}{|c|}{$* * * * \quad$ Administered $50 \mu \mathrm{g}$ per day for 4 weeks } \\
\hline
\end{tabular}

\section{Discussion}

The results of the present experiments confirm the previous reports that excess iodide has a goitrogenic activity in the chick (Wheeler and Hoffman 1948, 1949).

Radiochromatographic analysis of the chick thyroid for acute effect on iodine showed a decreased proportion of organic ${ }^{131} \mathrm{I}$ as well as thyronine ${ }^{131} \mathrm{I}$ and high MIT/DIT ratio, indicating that both the organic binding of iodine and synthesis of thyronine were depressed. In rats fed excess iodide for a long period, relative proportions of thyroidal ${ }^{131}$ I constituents were not different from the control (Galton and
Pitt-Rivers 1959; Braverman and Ingbar 1963; Wolff et al., 1949). The chronic iodine effect on the chick seems to be obviously different from the rat. There are a significant decrease in thyronine ${ }^{131} \mathrm{I}$ proportion and a rather low MIT/DIT ratio in the iodide-fed chicks, suggesting that iodide administered chronically sustains a decrease in the speed of thyronine ${ }^{131} \mathrm{I}$ formation by the chick thyroid.

Kobayashi and Gorbman (1960) showed no significant changes in the thyroidal radiocompounds in 9 day old chicks treated with $30 \mu \mathrm{g}$ of iodide per day for 8 days. While, Rosenberg et al. (1963a, b, 1964) reported a low MIT/DIT ratio and a decreased thyronine 


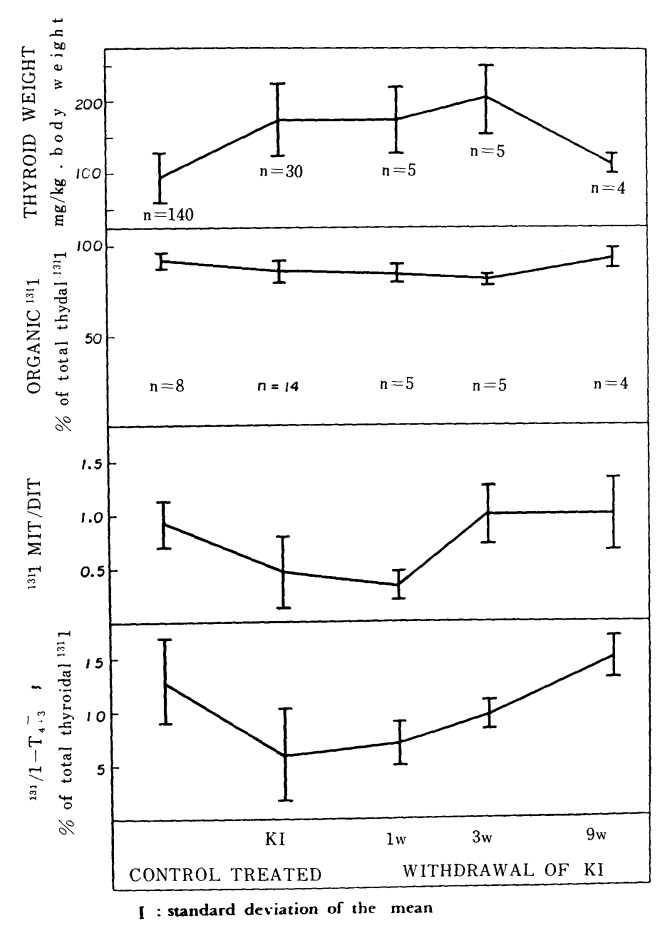

.Fig. 2. Change in thyroid weight and thyroidal radioiodinated compounds in the chicks during and after treatment with iodide. Thyroids were removed $4 \mathrm{hr}$. after $131 \mathrm{I}$. In the KI-treated chicks $1.0 \mathrm{mg}$ of carrier iodide was given simultaneously with $131 \mathrm{I}$.

Bracket indicates the standard deviation of the mean value.

131 I proportion in both chick and rat, fed on a diet containing 1 to $2 \mu \mathrm{g}$ of iodine per $\mathrm{g}$. These discrepant results might have arisen from their methodological differences such as dosage of iodine, age of animals or iodine content of diet. However, in our data, goiter is found only in the iodide fed chicks and a low MIT/DIT ratio as well as a decreased thyronine ${ }^{131}$ I proportion seems to be characteristic to the goitrous chick. Similar findings to the results were previously shown in our report (Suzuki et al., 1965), which indicated a decreased thyronine ${ }^{131}$ I proportion on endemic coast goiter. In addition, the fact that after discontinuation of iodide treatment the increased ${ }^{131} \mathrm{I}$ thyronine proportion would appear to support our view.

From the data obtained by estimation of iodide by a direct chemical method, it is evident that a treatment with iodide in the order of magnitude such as used in the present experiment, increases the absolute amount of intrathyroidal thyronine despite a decrease in its relative proportion.

The results of ${ }^{131} \mathrm{I}$-labelled thyroxine turnover study in the chicks pretreated with PTU or thyroxine, indicate that the half-life of radiothyroxine $\left(\mathrm{T}_{1} / 2\right)$ is a reliable index of the peripheral metabolism of thyroid hormone in chicks. The mean of thyroxine distribution space (TDS) obtained from the iodide-fed and control chicks were $309 \pm 96$ and $278 \pm 139$ $\mathrm{cc} / \mathrm{kg}$ of body weight respectively. Assuming that the degradation of stable thyronine can be expressed as $\mathrm{D}=\mathrm{TDS} \times(0.693 / \mathrm{T}) \times$ Plasma Thyronine Concentration, the mean $\mathrm{D}$ for the iodide-fed chick is $3.63 \mu \mathrm{g} / \mathrm{day} / \mathrm{kg}$ of body weight and 3.08 for the control. These data suggest that in the goitrous chicks the secretion of thyroid hormone from the gland does not change greatly notwithstanding a marked increase in intrathyroidal thyronine. It is generally accepted that thyronine stored in the gland is released by proteolysis of thyroglobulin. In iodine-treated chicks, the proteolytic activity of thyroglobulin was markedly decreased. But, decrease in proteolytic activity was shown also in iodine-treated rats (Takeuchi et al., 1969). Accordingly we believe that the inhibitory effect of chronic iodine treatment on the chick thyroid consists of the combined blocking of coupling of iodotyrosine and depression of proteolysis of thyroglobulin.

It is possible that the above combined block for both synthesis and release of thyronine may initially reduce the amount of hormone secretion and then, depending on compensatory increase in $\mathrm{TSH}$, produce hypertrophy of the thyroid and maintain euthyroidism.

\section{Acknowledgment}

The authors wish to thank Professor Keimei 
Mashimo for helpful advice in these experiments.

\section{References}

Braverman L. and S. H. Ingbar (1963). J. Clin. Invest. 42, 1216.

Galton V. A. and R. Pitt-Rivers (1959). Endocrinology 64, 835.

Gross W. G., L. K. Wood and J. S. McHargue (1948). Analyt. Chem. 20, 900.

Grossman A. and G. F. Grossman (1955). $J$. Clin. Endocrinol. 15, 354.

Ingbar S. H. and N. Freinkel (1955). J. Clin. Invest. 34, 808.

Kobayashi H. and A. Gorbman (1960). Endocrinology 66, 795.

Morgans M. E. and W. R. Trotter (1953). Lancet 2, 1335.

Pileggi V. J., N. D. Lee, O. J. Golub and R. J. Henry (1961). J. Clin. Endocrinol. 21, 1272.

Pileggi V. J., H. A. Segal and O. J. Golub (1964). Ibid. 24, 273.
Pitt-Rivers S. R. (1960). Ann. N. Y. Acad. Sci. 86, 362.

Pitt-Rivers R., V. A. Galton and N. S. Halmi (1958). Endocrinology 63, 699.

Roche J., S. Lissitzy and R. Michel Method of Biochemical Analysis Vol. 1, Intersci. Publ., New York p. 243 (1954).

Rosenberg L. L., M. K. Dimick and G. LaRoche (1963a). Endocrinology 72, 749.

Rosenberg L. L., G. LaRoche and M. K. Dimick (1963b). Ibid. 72, 759.

Rosenberg L. L., M. Goldman, G. LaRoche and M. K. Dimick (1964). Ibid. 74, 212.

Suzuki H., T. Higuchi, K. Sawa, S. Ohtaki and Y. Horiuchi (1965). Acta Endocrinol. 50, 161.

Suzuki M. (1958). Endocrinol. Japon. 3, 291.

Takeuchi K., H. Suzuki, M. Sawada and Y. Horiuchi (1969). Endocrinology in press.

Wheeler R. S. and E. Hoffman (1948). Ibid. 43, 430 .

Wheeler R. S. and E. Hoffman (1949). Proc. Soc. Exptl. Biol. Med. 72, 250.

Wolff J., I. L. Chaikoff, R. C. Gokiberg and J. R. Meier (1949). Endocrinology 45, 504. 